\title{
Conservation of European wild rabbit populations when hunting is age and sex selective
}

\author{
Carlos Calvete $^{\mathrm{a}, *}$, Elena Angulo ${ }^{\mathrm{b}}$, Rosa Estrada ${ }^{\mathrm{a}}$

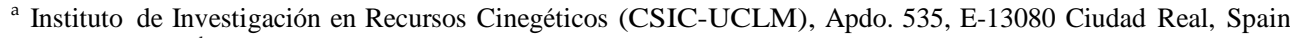 \\ ${ }^{\mathrm{b}}$ Estación Biológica de Doñana (CSIC), Apdo. 1056, E-41080 Sevilla, Spain
}

\begin{abstract}
Several predator species at risk of extinction in Southwestern Europe are dependent on the population density of European wild rabbits Oryctolagus cuniculus. Rabbit populations in the region, however, have recently undergone dramatic decreases in population density, which may be exacerbated by hunting. Current hunting policies set the autumn-winter season, just before the start of rabbit reproduction, as the main hunting season, and previous theoretical models have estimated that the current hunting season may have the greatest negative impact on rabbit abundance and should be changed. We utilised a model for rabbit population dynamics to determine the effects of the timing of hunting during two seasons, summer and autumn, on the tendency of rabbit populations to be over-harvested and on the number of rabbits hunted. This model included field estimates of age- and sex-selection biases of hunting by shotgun. Scenarios with different hunting rates and sex- and age-selection probabilities of hunting were simulated for populations with different turnover levels and with and without compensatory mortality mechanisms. Field estimations showed that hunting in summer was juvenile-biased whereas autumn hunting was juvenile- and male-biased. In contrast to previous findings, our modelling results suggested that hunting in autumn may be the most conservative option for harvesting of rabbit populations, since these populations were more prone to be over-harvested during the summer. The differences between the two seasons in number of rabbits hunted were dependent on population dynamics and hunting sex- and age-selection probabilities. Our findings suggest that altering of current hunting policies would not optimise the exploitation or conservation of wild rabbit populations, but that the latter may be improved by some changes in the timing of hunting.
\end{abstract}

Keywords: Hunting selection; Hunting timing; Oryctolagus cuniculus; Sex-age hunting biases; Sustainable harvesting

\section{Introduction}

The European wild rabbit is one of the most important vertebrate prey species in southwestern Europe Mediterranean ecosystems, and several predator species threatened with extinction, including the Iberian lynx (Lynx pardina) and the imperial eagle (Aquila adal-

\footnotetext{
* Corresponding author. Present address: Pza. Serrano Berges 13, 80 D. 50.058 Zaragoza, Spain. Tel.: +34-976-761-611; fax: +34-976761-612.

E-mail address: vetecal2003@jazzfree.com (C. Calvete).
}

berti), depend on high rabbit densities (Delibes and Hiraldo, 1981). Myxomatosis, which first appeared in Iberian rabbit populations in the 1950s, caused a substantial reduction in rabbit population density and significant changes in their distribution (Muñoz, 1960). Further reductions in rabbit abundance were observed following the arrival of viral haemorrhagic disease (VHD) to Spain in 1988, and, when this disease became enzootic in wild populations, many of these populations continued decreasing, some to the point of extinction (Argüello et al., 1988; Villafuerte et al., 1995; Calvete et al., 2002). 
Rabbit populations in Spain have been traditionally harvested by hunting. Despite the recent history of dramatic decreases or even extinction of many rabbit populations, rabbits are still considered the primary small game species for sport hunting in Spain, with about four million rabbits hunted every year (Ministry of Agriculture, Fisheries and Food, 1996). Currently, rabbits can be hunted during two seasons each year: the summer (July and August) and the autumn-winter (October through January). The summer hunting season usually occurs just after the rabbit breeding period, whereas the autumn-winter hunting season occurs at the start of reproductive activity. Although hunting in summer has usually been authorised to control rabbit populations and to prevent future crop damage, the autumnwinter hunting season has been traditionally considered the main rabbit hunting period. Harvesting before reproduction is not a usual practice in the harvesting of wild populations, since it leads to reductions in the size of the stable population and sustainable yield (Kokko and Lindström, 1998). Although rabbits are native to Spain, they have been mainly harvested before reproduction, probably because they have been considered historically as a pest species due to the huge economic losses they have caused to agriculture (Muñoz, 1960). Following the sharp decline of rabbit populations in the last decades, and the risk of extinction of any predator species dependent on rabbit abundance (Palma et al., 1999; Palomares, 2001; Rodríguez and Delibes, 2003), the current policies of timing of hunting may be inadequate for the conservation of rabbits and endangered predator species (REGHAB, 2002).

The first theoretical publications on the timing of species control, addressing rabbit populations in New Zealand (Darwin and Williams, 1964) and England (Smith and Trout, 1994), suggested that the timing of rabbit control affects the growth rate of populations in an age-dependent manner. Results from these models suggested that the timing of hunting in Spain is not optimal for the conservation of Iberian wild rabbit populations. Recently, Angulo and Villafuerte (2003) used modeling to assess the impact of the timing of hunting and hunting pressure under several hunting age-selection strategies, on an Iberian wild rabbit population for conservation purposes, and concluded that hunting in late spring should have the smallest negative impact on these populations.

One of the main assumptions of this model, and of models developed previously (Darwin and Williams, 1964; Smith and Trout, 1994), however, was based on a lack of data on the potential age or sex biases of hunting. These theoretical works showed that the nature and degree of hunting selection (e.g., age-selection) determine to a great extent the optimal timing of hunting to optimize hunting extraction. However, the true selection mechanisms of hunting were unknown in these works. As suggested by Daly (1980) and Smith et al. (1995), hunting and capture can be sex- and age-selective depending on of the method used and season. Therefore, to assess the effects of timing of hunting on wild rabbit populations by modeling, it is first necessary to know the selectivity of the hunting.

The most common and widely used method to hunt wild rabbits in the Iberian Peninsula is by shotgun. To our knowledge, however, there is no estimation of hunting selection by this method. Moreover, from the viewpoint of sport hunting, rabbits, being a game species, should only be allowed when the population is comprised of subadult and/or adult individuals. Hunting in late spring, which would optimize hunting extraction and conserve rabbit populations (Angulo and Villafuerte, 2003), would involve hunting of very young rabbits. As hunters may refuse to change the main hunting period to late spring for ethical and sporting reasons, hunting extraction must reconcile ecological features of the game species with these hunting needs. Therefore, under these conditions, the most reasonable period to hunt rabbits for sport in Spain may be period that includes both current hunting seasons (summer and autumn-winter, i.e., from July to December).

A second main assumption of the model of Angulo and Villafuerte (2003) was that there was no population density dependence and thus no compensatory mechanisms, either in fecundity or in mortality. Several works have suggested that seasonal compensation of mortality in wild populations is needed to determine sustainable harvesting (Jensen, 1996; Smith, 1997; Kokko and Lindström, 1998; Boyce et al., 1999). Compensatory mechanisms can include density-dependent changes in reproduction and/or mortality. In wild rabbits, density-dependent changes at intermediate rabbit densities seem to be comprised primarily of changes in the mortality of young rabbits, because density-dependent increases in the length of the breeding season, litter size or proportion of females producing litters seem to occur only under conditions of very low population density (Trout and Smith, 1998; Twigg and Williams, 1999). In fact, the population dynamics of the rabbit seems to be more sensitive to changes in mortality level (particularly juvenile mortality) than to changes in fecundity (Smith and Trout, 1994; Smith, 1997).

The population dynamics of wild rabbit populations show a high degree of variation between years and areas, with highly different mortality rates and turnover of populations (Tyndale-Biscoe and Williams, 1955; Wheeler and King, 1985; Gibb, 1993). Researchers who have assessed the impact of the timing of hunting have incorporated this variation into their models, simulating rabbit populations under several scenarios with different natural mortality rates of young rabbits. These scenarios utilize populations with different baseline growth rates, and the simulations performed showed 
that the higher the baseline population growth rate (or the better the quality of population dynamics), the higher will be the sustainable hunting pressure supported by the population (Darwin and Williams, 1964; Smith and Trout, 1994; Angulo and Villafuerte, 2003). Variation in turnover levels may be a confounding variable in evaluating the impact of hunting on real populations, however, to our knowledge, the impact of the timing of hunting under varying levels of population turnover has not been evaluated; i.e., the impact of hunting on several populations with different natural mortality rates and fecundity, but with a growth rate equal to zero (stable populations).

For these reasons, we have sought to improve the model of Angulo and Villafuerte (2003) to obtain a more precise theoretical assessment of the optimal hunting season of wild rabbits in the Iberian Peninsula, in order to conserve their populations. We focused our attention on the period, we considered most reasonable to hunt rabbits for sport (July-December), which overlaps the two current hunting seasons in Spain. The main improvement of the present work was to obtain estimates of the hunting selection probability ratios on the different sexes and age classes of rabbits, hunted by the members of a hunting association during the two currently established open hunting seasons. The resulting hunting selection probability ratios were incorporated into our model to simulate hunting in both current hunting seasons under different population dynamics, including scenarios with compensatory mechanisms and different turnover levels.

\section{Methods}

\subsection{Hunting selection probability ratios estimation}

The study was performed in 1999, in the Central Ebro Valley, Zaragoza Province, NE Spain, an area characterised by a temperate continental Mediterranean climate with little rain (20 year; mean $=250 \mathrm{~mm}$ ). The wild rabbit population chosen for the study was located in a 1500-ha area representative of the Mediterranean ecosystem of the valley. The landscape consisted of low hillocks interspersed with fields of wheat and barley. The natural vegetation was sparse steppe shrub that it was restricted to the hillock regions. It had a mean height $<50 \mathrm{~cm}$, and a $30 \%$ cover.

The local hunting association carries out the management of small game species populations in this study area, and hunts using shotguns in the two yearly hunting seasons allowed by the Regional Government of Aragón for wild rabbits. The periods are summer (July 25-August 24 in 1999) and autumn (October 17-November 30 in 1999). The autumn hunting season is usually prolonged over the winter (i.e., from
December to mid-January), to allow hunting of rabbits in crops.

To estimate the probability ratios associated with rabbits of a given sex and age being hunted, we estimated the sex and age structure of the rabbit population before the start of each hunting season. This estimation was performed by live trapping of rabbits from July 9 to July 24 for the summer season, and from September 29 to October 16 for the autumn season. It is known that estimation of age and sex structure of wild rabbit populations is conditioned by the bias of samples, determined by the trap response of individuals, activity and habitat use (Daly, 1980; Shepherd et al., 1981; Smith et al., 1995). In our study area, due to the low shrub cover, most of the rabbits used warrens as refuges throughout the year. To catch live rabbits, we used smeuse traps, consisting of rabbitproof wire mesh netting around individual warrens, with one-directional doors set on trap boxes at all exit points (5-20 per warren). To lessen the possible age and sex bias of our samples, the traps were installed after noon, at the time of highest daily temperature and, therefore, the time of lowest rabbit activity outside the warrens. Prior to erecting the netting, we carried out a battue in the area around the warren, looking for rabbits resting on the soil surface and ensuring that they took refuge in the warrens. Traps were visited twice daily. Trapped rabbits were sexed, identified with numbered metallic ear-tags, and classified as juveniles (up to 8 months) or adults (over 8 months) by the external assessment of the degree of ossification of the tibial and distal ulnar epiphyses (Watson and Tyndale-Biscoe, 1953). After sex and age determination, rabbits were released into the nearest warrens. Traps were set around each warren until no rabbits were trapped and there were no signs of rabbit activity (tracks, fresh faeces or urine) in the netted area, which occurred 3-7 days after the traps were erected.

To estimate sex and age structure of the hunted rabbits bagged during both open hunting seasons, we determined the sex and age of rabbits killed by hunters at the end of each hunting day. The total number and distribution of hunted rabbits was not known, however, since it was not possible to examine the hunting bag of all hunters. During the autumn hunting season we sampled only rabbits hunted by shotgun, ending the sampling when hunters began to use ferreting as their hunting method (i.e., beginning December 1).

Statistical estimation of probability ratio of being hunted associated with sex $\left(\mathrm{PR}_{\mathrm{x}}\right)$ and age $\left(\mathrm{PR}_{\mathrm{y}}\right)$ of rabbits was performed by adjusting a logistic regression model to the data of rabbits hunted and captured alive for each hunting open season. Sex, age and their interaction were the independent variables in the initial regression model, with the final model obtained by a backward elimination procedure. 


\subsection{Structure of the model}

We constructed a deterministic, discrete model to simulate the population dynamics of wild rabbits in the study area, similar to that of Angulo and Villafuerte (2003). Following the results on survival in a wild rabbit population located near the study area (Calvete et al., 2002), we divided the rabbit population into three age classes: new-born (n), juveniles (j) and adults (a). Gestation in rabbits lasts about 28-30 days, and female rabbits can be fertilised few days after parturition. New-borns are rabbits under 1 month of age. Since they live in a breeding stop (a burrow excavated in the soil) during about the first 3-4 weeks of age and depend on their mother for survival, we considered their mortality the same as that of adult females. We assumed that at birth, the sex ratio of young rabbits is 0.5 (Myers and Poole, 1962; Boyd, 1985). Juveniles (j) were young and immature non-reproductive rabbits between 2 and just 8 months of age (j2-j8, respectively), whereas adults (a), the only reproductive class, were rabbits older than 8 months of age. The model was run on a monthly time step for the transit time among age classes. Letting D, $\mathrm{M}, \mathrm{R}$, and $\mathrm{F}$ denote population density, mortality rate, proportion of pregnant females and fecundity, respectively, the resulting age-class population was represented by the following discrete time equations:

$\mathrm{Dn}_{\tilde{\mathrm{t} t}} 1 / 4$ 0:5 $\times \mathrm{Da}_{\tilde{\partial} \mathrm{t}-1 \mathrm{p}} \times \mathrm{R}_{\tilde{\partial t}-1 \mathrm{p}} \times \mathrm{F} \times \mathrm{Dt}$

$\operatorname{Dj} 2_{\tilde{\partial t p}} 1 / 4 \mathrm{Dn}_{\tilde{\partial t}-1 \mathrm{p}} \times ð 1-\mathrm{MaP} \times \mathrm{Dt} ;$

$D j 3_{\partial t p} 1 / 4 \operatorname{Dj} 2_{\delta t-1 p} \times ð 1-M j P \times D t ;$

$\operatorname{Dj} 4_{\partial t p} 1 / 4 \operatorname{Dj} 3_{\partial t-1 p} \times ð 1-M j p \times D t ;$

$\operatorname{Dj} 5_{\delta \mathrm{tp}} 1 / 4 \mathrm{Dj} 4_{\partial t-1 p} \times ð 1-\mathrm{MjP} \times \mathrm{Dt} ;$

$\operatorname{Dj} 6_{\partial t \mathrm{t}} 1 / 4 \mathrm{Dj} 5_{\partial t-1 p} \times ð 1-\mathrm{MjP} \times \mathrm{Dt} ;$

$\operatorname{Dj} 7_{\partial t p} 1 / 4 \operatorname{Dj} \sigma_{\partial t-1 p} \times ð 1-M j P \times D t ;$

$\operatorname{Dj} 8_{\delta t p} 1 / 4 \operatorname{Dj} 7_{\gamma t-1 p} \times ð 1-M j P \times D t ;$

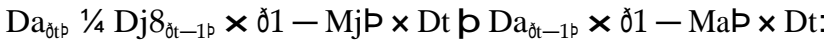

ðр

The population model (Eqs. (1)-(9)) was solved using the software Stella research 5.1.1 (High-Performance Systems, 1997). Although there is some natural sex-dependent mortality in natural populations (Cowan, 1987), it was not considered in order to simplify the model. The model did not include migration because it was assumed that emigration balances immigration. Following the model of Angulo and Villafuerte (2003), we incorporated into our model a seasonal pattern of adult natural mortality, since it is a more realistic pat- tern than the assumption of a constant mortality rate over the entire year. This seasonal pattern is induced by predator response to the over-abundance of young rabbits during the rabbit breeding season, with some predators selecting active young rabbits (Donázar and Cevallos, 1989). If this seasonal mortality pattern is not included in the model, and if there are no other compensatory mechanisms, then there would be no optimal season for sustainable harvesting when non-selective hunting regarding the age of rabbits is simulated (Darwin and Williams, 1964; Smith and Trout, 1994; Smith, 1997). Thus, the performance of our model was enhanced with the inclusion of the pattern.

We improved the basic modeling of Angulo and Villafuerte (2003) by running the model under two scenarios with different degrees of compensatory juvenile mortality. First, we assumed no compensation of mortality. Second, the juvenile mortality rate was proportionately reduced for each month by the ratio between current and baseline population size for that month, when the population was not harvested by hunting, following equation (Smith, 1997):

$\mathrm{Mj}_{\text {new }} 1 / 4 \mathrm{Mj}_{\text {old }} \times ð 1-\mathrm{c} \times ð 1-\mathrm{rpp}$;

where $\mathrm{Mj}_{\text {old }}$ is the original monthly mortality rate, $\mathrm{Mj}_{\text {new }}$ is the adjusted mortality rate, $\mathrm{r}$ is the population size ratio following hunting, and $\mathrm{c}$ is the level of compensation $(06$ с 61$)$. As we sought to evaluate the impact of timing of hunting, we only simulated the highest level of compensation $(c=1)$ in order to compare these results with those obtained under non-compensatory simulations.

To model different population turnover levels, we simulated four scenarios, the first with mortality rates obtained by Calvete et al. (2002), and the other three by proportionately increasing the estimated mortality rates for all age-classes by $10 \%, 20 \%$ and $30 \%$.

\subsection{Parameterisation of the model}

All data used in our study were taken from the survey of Calvete et al. (2002), who estimated mortality rates and the proportion of reproductive females over several years in a population located approximately $30 \mathrm{~km}$ from our study area. Adult mortality rates and the proportion of reproductive females were monthly averaged for all years of the study. The monthly mean adult mortality rates used in the model were derived from bimonthly estimates, whereas for the juvenile age class, due to the insufficient data, only one monthly mortality rate was averaged from 1 to 7 months of age (Table 1).

Although the fecundity of the population surveyed by Calvete et al. (2002) was not known, as a first approximation we set the mean litter size at 3.5, a value established by Angulo and Villafuerte (2003) and in accordance with previous studies carried out in Spain 
Table 1

Proportion of reproductive females and mortality rates used in the model

\begin{tabular}{llll}
\hline Month & $\begin{array}{l}\text { Proportion of } \\
\text { reproductive females }\end{array}$ & $\begin{array}{l}\text { Adult } \\
\text { mortality rate }\end{array}$ & $\begin{array}{l}\text { Juvenile } \\
\text { mortality rate }\end{array}$ \\
\hline July & 0 & 0.023 & 0.151 \\
August & 0 & 0.023 & 0.151 \\
September & 0 & 0.071 & 0.151 \\
October & 0 & 0.071 & 0.151 \\
November & 0.1 & 0.086 & 0.151 \\
December & 0.4 & 0.086 & 0.151 \\
January & 0.4 & 0.026 & 0.151 \\
February & 0.6 & 0.026 & 0.151 \\
March & 0.6 & 0.027 & 0.151 \\
April & 0.6 & 0.027 & 0.151 \\
May & 0 & 0.038 & 0.151 \\
June & 0 & 0.038 & 0.151 \\
\hline
\end{tabular}

(Soriguer, 1981a), and set the starting population at 5000 adult rabbits. We then ran the model for 2 years to obtain an age-structured initial population at the start July month, which was used to seed the model for each run. We reran the model with different values for litter size until reaching a stable population (yearly growth rate $=0$ ) for the four scenarios with different turnover levels. The litter sizes estimated to stabilise non-harvested populations were $2.33,2.84,3.42$ and 4.1 for mortality increases of $0 \%, 10 \%, 20 \%$ and $30 \%$, respectively. Densities of stable non-harvested populations were considered as baseline population sizes for each scenario.

\subsection{Modelling hunting strategies}

Following Angulo and Villafuerte (2003), we assumed that hunting mortality was additive to natural mortality (Trout and Tittensor, 1989). We simulated hunting during the same 2-month open seasons used to harvest rabbits in our study; i.e., a summer season (July-August) and an autumn season (October-November). The percentage of the rabbit population hunted during each hunting month represented the hunting rate or hunting pressure. We simulated an increasing hunting rate from $2 \%$ to $20 \%$, in $2 \%$ steps. The probability of being hunted was sex and/or age dependent. The hunting rate for each age and sex class of rabbit was calculated by the following equation: entire rabbit population (simulated from $2 \%$ to $20 \%$ ), and $D_{x y}$ is the density of rabbits of sex-class $x$ and age-class $y$, with $D_{x y}$ being the density of the entire rabbit population. $\mathrm{PR}_{\mathrm{xy}}$ was calculated as the product of the probability ratio of sex-class $x\left(P_{x}\right)$ and the probability ratio of age-class y $\left(\mathrm{PR}_{\mathrm{y}}\right)$ (Selvin, 1996). We ran the model for seven degrees of sex- and ageselection, with one being a no-selection simulation, and six being simulations with values calculated from the mean sex-and age-probability ratios estimated from logistic regression, from $-1.5 \mathrm{SE}$ to $+1 \mathrm{SE}$ in $0.5 \mathrm{SE}$ steps. Thus, simulations were carried out with degrees of sex- and age-selection included approximately within the $90 \%$ confidence interval of field estimations.

We ran 1120 representative scenarios resulting from the combinations of 10 hunting pressures, two hunting seasons, two juvenile mortality density dependence scenarios, four scenarios of population turnover, and seven scenarios with different degrees of sex- and age-selection. To simulate each scenario the model was run for 3 years. Running of the model started at the beginning of July and ran for 2 years with the baseline population, and hunting was only simulated during the third year. We assessed the impact of the timing of hunting by analysing the relation of hunting pressure and number of rabbits hunted with the growth rate of the population $(k-1)$. Growth rate was estimated by comparing the baseline population at the start of July of the third year with that at the end of simulation (equivalent to the population at the beginning of July of a fourth year). The population size was declining when $(\mathrm{k}-1)<0$ and stable when $(k-1)=0$. Growth rate was measured after the breeding season of populations, since at equilibrium these two sizes must be equal and subsequent yearly intervals would only repeat the pattern observed within the third year (Kokko and Lindström, 1998).

We analysed the relationship between hunting pressure and growth rate within and between scenarios because it reflects the tendency of rabbit populations to be over-harvested when hunting pressure increases. Due to model design, the relationship between growth rate and hunting pressure was lineal within scenarios. Thus, for each scenario we estimated the slope of the growth rate in relation to hunting pressure by adjusting a simple regression model with no intercept, where hunt-

$$
\mathrm{H}_{\mathrm{x}, \mathrm{y}} 1 / 4 \mathrm{PR}_{\mathrm{xy}} \times \mathrm{H}_{\mathrm{p}} \times{ }^{\mathbf{X}} \mathrm{D}_{\mathrm{xy}}{ }^{-}-\mathrm{PR}_{\mathrm{fa}} \times \mathrm{D}_{\mathrm{fa}} \mathrm{p} \mathrm{PR}_{\mathrm{fj}} \times \mathrm{D}_{\mathrm{fj}} \mathrm{p} \mathrm{PR}_{\mathrm{ma}} \times \mathrm{D}_{\mathrm{ma}} \mathrm{p} \mathrm{PR}_{\mathrm{mj}} \times \mathrm{D}_{\mathrm{mj}}
$$

where $\mathrm{H}_{\mathrm{xy}}$ is the hunting rate for the sex-class $\mathrm{x}$ ( $\mathrm{f}=\mathrm{fe}-$ male, $\mathrm{m}=$ male) and age-class y $(\mathrm{a}=$ adult, $\mathrm{j}=$ juvenile), $\mathrm{PR}_{\mathrm{xy}}$ is the probability ratio of being hunted for sexclass $\mathrm{x}$ and age-class $\mathrm{y}, \mathrm{H}_{\mathrm{p}}$ is the hunting ratio for the ing pressure was the independent variable and growth rate the dependent variable. The value of the estimated slope thus represented the decrease in population growth rate per $1 \%$ increase in hunting pressure. The 
lower the slope, the higher the tendency of rabbit populations to be over-harvested when hunting pressure increases. Aside from the tendency toward over-harvesting, it is important to analyse the number of rabbits hunted, since one goal of optimising the timing of hunting of wild rabbits is to maximise the number of hunted rabbits while minimising the impact of hunting on rabbit population growth. To analyse this, as the relationship between growth rate and number of hunted rabbits was else lineal within scenarios, we estimated the slope of a simple regression model with no intercept between growth rate (as the dependent variable) and number of rabbits hunted (as the independent variable) within each scenario. The slope represents the decrease in population growth rate per hunted rabbit. Thus, the lower the slope, the higher the negative impact on growth rate per hunted rabbit and the lower the number of rabbits that will be available to be hunted.

\section{Results}

\subsection{Hunting selection probability ratios estimation}

Sex- and age-structure of live-trapped samples were clearly different from that of hunted samples during both hunting seasons (Table 2). The logistic model adjusted to summer data $\left(\mathrm{v}^{2}=24.9, \mathrm{df}=1, \mathrm{P}<0.001\right)$ showed that juveniles had a probability ratio of being hunted $( \pm$ SE) $5.06 \pm 1.39$ times higher than that of adults $(\mathrm{B}=$ $1.62 \pm 0.33$, Wald $=23.79, \mathrm{df}=1, \mathrm{P}<0.001)$, but no sex-related difference was found $(\mathrm{P}=0.622)$.

Analysis of the autumn data detected a more complex pattern of hunting selection as functions of sex and age. The final adjusted logistic model $\left(\mathrm{v}^{2}=31.14, \mathrm{df}=2\right.$, $\mathrm{P}<0.001$ ) showed that juveniles had a probability ratio of being hunted $2.89 \pm 1.4$ times higher than that of adults $(\mathrm{B}=1.06 \pm 0.36$, Wald $=8.66, \mathrm{df}=1, \mathrm{P}=0.003)$, and males had a probability ratio of being hunted $5.7 \pm 1.5$ times higher than that of females $(\mathrm{B}=1.74 \pm$ 0.39 , Wald $=19.49, \mathrm{df}=1, \mathrm{P}<0.001$ ). From sex- and age-related probability ratios estimated by logistic models, we calculated the respective $P_{x y}$ of each sex and age class of rabbit for the seven simulated scenarios of hunting selection (Table 3).

\subsection{Simulations}

In all cases, when hunting was not selective, rabbit populations were more prone to be over-harvested during the autumn than during the summer (Fig. 1). When some degree of sex- and age-selection was simulated, however, the model exhibited different outcomes. For all simulated degrees of selection, the combined sex and age hunting selection in the autumn

Table 2

Number of rabbits live-trapped before the start of hunting seasons (population sample) and number of hunted rabbits sampled (hunting sample)

\begin{tabular}{llllll}
\hline & \multicolumn{2}{l}{ Summer } & & & Autumn \\
\cline { 2 - 3 } & Population sample & Hunting sample & & Population sample & Hunting sample \\
\hline Adult males & $15(14.4)$ & $6(2.6)$ & $11(4.8)$ & $24(26.4)$ & $20(29)$ \\
Adult females & $15(14.4)$ & $117(51.1)$ & $26(28.6)$ & $2(2.9)$ \\
Juvenile males & $36(34.6)$ & $95(41.5)$ & $22(24.9)$ & $37(53.6)$ & $10(14.5)$ \\
Juveniles females & $38(36.6)$ & 229 & 91 & 69 \\
Overall & 104 & & & \\
\hline
\end{tabular}

Percentages (\%) of each sex- and age-class within each sample are in parenthesis.

Table 3

Probability ratio (PR) of being hunted of rabbits as simulated according to scenarios with different degrees of sex- and age-selection

\begin{tabular}{|c|c|c|c|c|c|c|c|c|}
\hline & \multicolumn{4}{|c|}{ Summer } & \multicolumn{4}{|c|}{ Autumn } \\
\hline & $\mathrm{PR}_{\mathrm{ma}}$ & $\mathrm{PR}_{\mathrm{fa}}$ & $\mathrm{PR}_{\mathrm{mj}}$ & $\mathrm{PR}_{\mathrm{fj}}$ & $\mathrm{PR}_{\mathrm{ma}}$ & $\mathrm{PR}_{\mathrm{fa}}$ & $\mathrm{PR}_{\mathrm{mj}}$ & $\mathrm{PR}_{\mathrm{fj}}$ \\
\hline No selection & 1 & 1 & 1 & 1 & 1 & 1 & 1 & 1 \\
\hline Mean PR - 1.5 SE & 1 & 1 & 3.1 & 3.1 & 3.1 & 1 & 5.3 & 1.7 \\
\hline Mean PR - SE & 1 & 1 & 3.6 & 3.6 & 3.8 & 1 & 7.6 & 2 \\
\hline Mean PR - 0.5 SE & 1 & 1 & 4.3 & 4.3 & 4.7 & 1 & 11.3 & 2.4 \\
\hline Mean PR & 1 & 1 & 5.1 & 5.1 & 5.7 & 1 & 16.5 & 2.9 \\
\hline Meand PR + 0.5 SE & 1 & 1 & 6 & 6 & 6.9 & 1 & 24.1 & 3.5 \\
\hline Mean PR + SE & 1 & 1 & 7 & 7 & 8.4 & 1 & 34.4 & 4.1 \\
\hline
\end{tabular}

The seven scenarios included a no selection simulation and six simulations with values calculated from the mean sex and probability ratios estimated from logistic regression from $-1.5 \mathrm{SE}$ to $+1 \mathrm{SE}$ in $0.5 \mathrm{SE}$ steps $(\mathrm{m}=$ male, $\mathrm{f}=$ female, $\mathrm{a}=$ adult, $\mathrm{j}=$ juvenile $)$. 


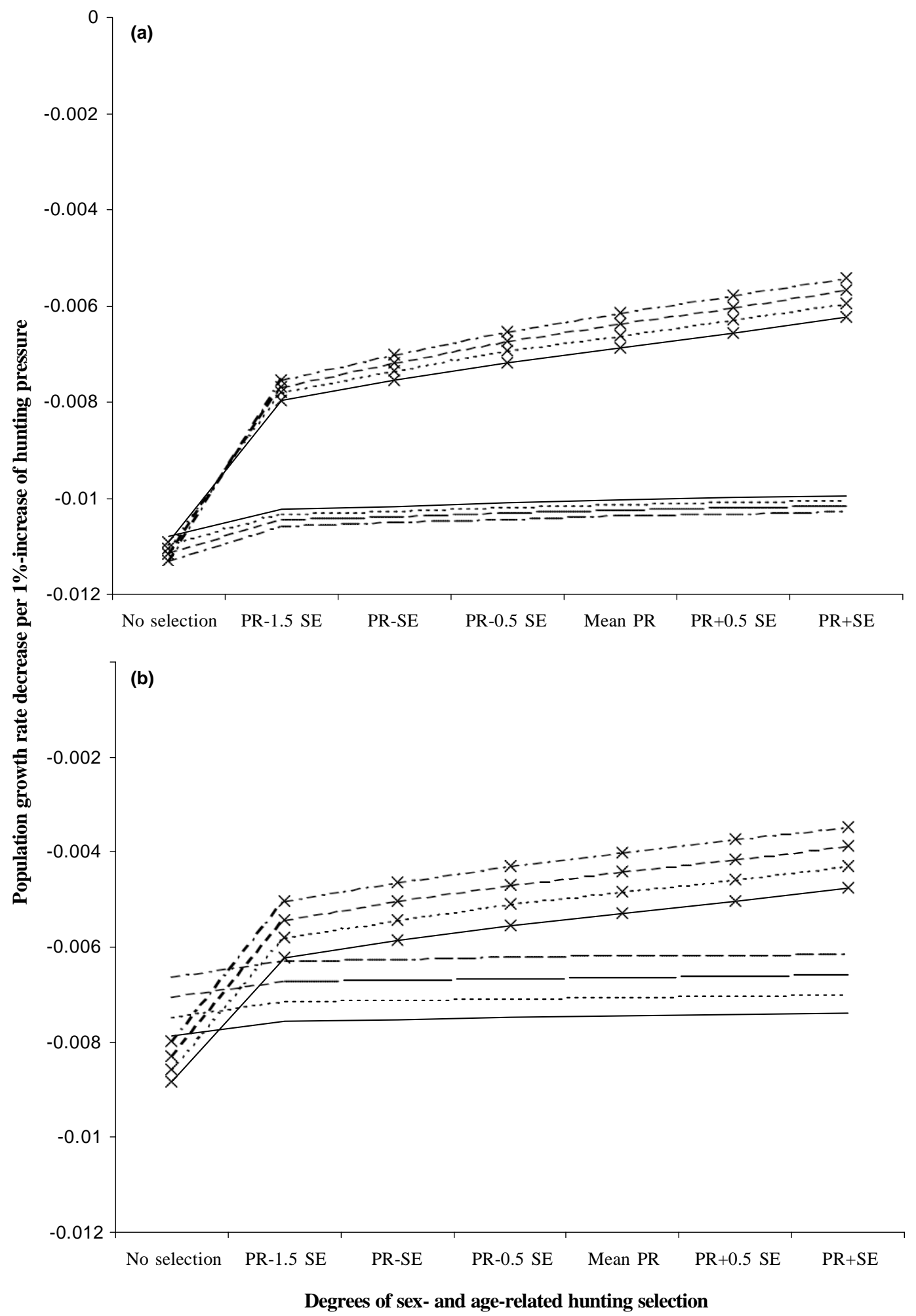

Fig. 1. Population growth rate decrease per $1 \%$ increase in hunting pressure under varying degrees of sex- and age hunting selection. Mean probability ratio (PR) and SE were estimated by logistic regression. Results of simulation (a) without and (b) with compensatory juvenile mortality. Baseline mortality rates (continuous lines), 10\% increased mortality rates (dotted lines), 20\% increased mortality rates (dashed lines), and 30\% increased mortality rates (dotted-dashed lines). Summer hunting season (lines without marks), autumn hunting season (lines with - marks).

season resulted in a lower tendency to be over-harvested than the age-only selection during the summer season. Moreover, when the degree of selection in- creased, the tendency to be over-harvested decreased more rapidly during the autumn than during the summer. 
As expected, compensatory juvenile mortality reduced the tendency to be over-harvested for all simulations. It also reduced the difference in the impact of hunting in different seasons when selection was simulated. The pattern of tendency to be over-harvested was qualitatively similar to results of the model without mortality compensation. The variation of turnover did not substantially change the qualitative pattern of the impact of hunting pressure on growth rate between hunting seasons. When hunting was carried out in summer, the tendency to be over-harvested was directly associated with increased turnover under non-compensatory

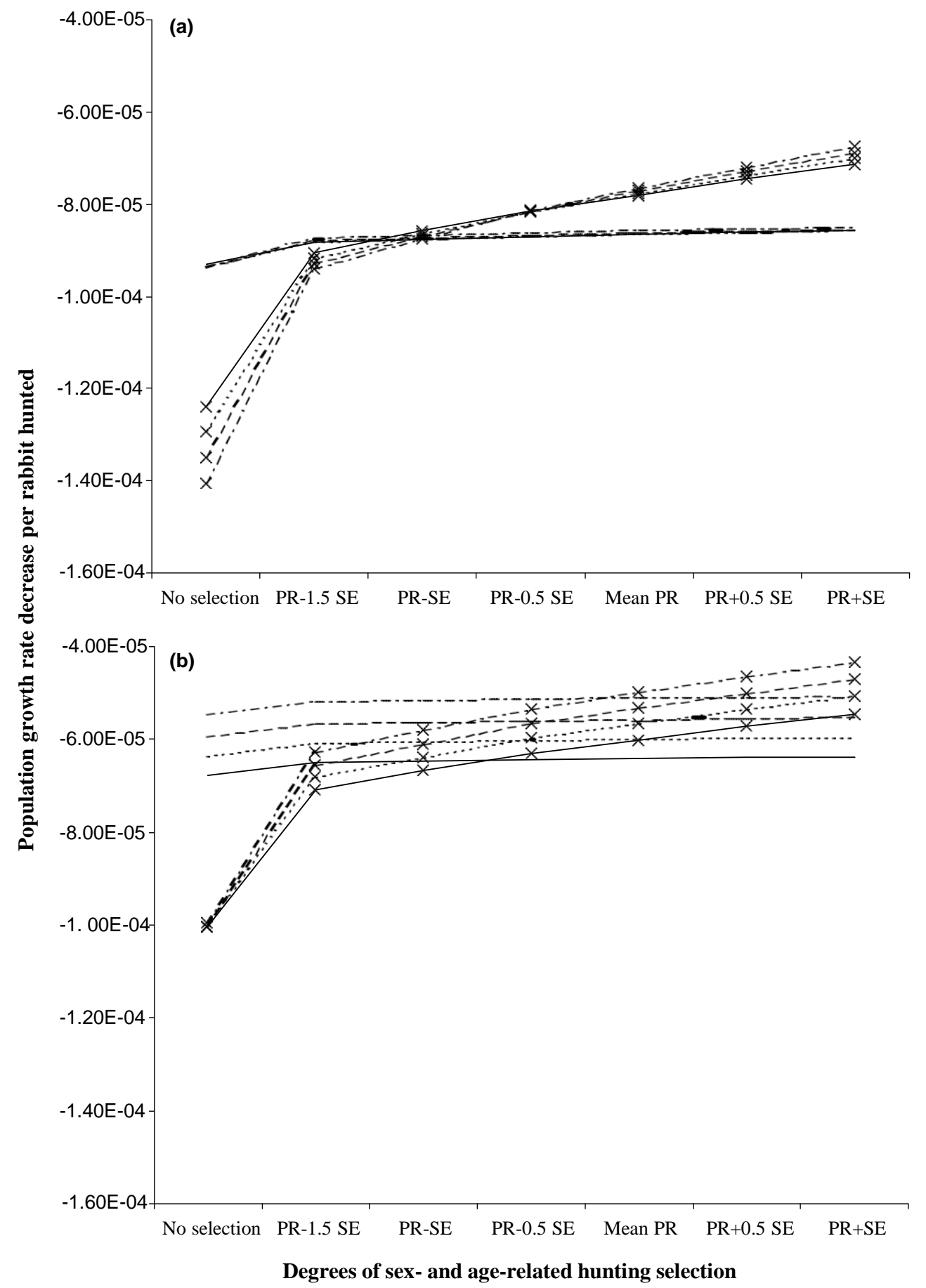

Fig. 2. Population growth rate decrease per hunted rabbit under varying degrees of sex-and age hunting selection. Mean probability ratio (PR) and SE were estimated by logistic regression. Results of simulation (a) without and (b) with compensatory juvenile mortality. Baseline mortality rates (continuous lines), 10\% increased mortality rates (dotted lines), 20\% increased mortality rates (dashed lines), and 30\% increased mortality rates (dotted-dashed lines). Summer hunting season (lines without marks), autumn hunting season (lines with - marks). 
mortality conditions, but it was inversely associated with increased turnover when the model simulated compensatory conditions. When hunting was simulated in autumn months, the results were similar under the two scenarios of compensatory and non-compensatory mortality. Tendency to be over-harvested was lower in populations with higher turnover and, as expected, differences between turnover scenarios were higher under conditions of compensatory mechanisms. When no sex- and age selection was simulated within noncompensatory mortality scenarios, however, turnover levels were directly associated with a tendency to be over-harvested.

Regarding the number of rabbits that could be hunted in simulated populations (Fig. 2), our results showed that when no sex- and/or age-selection was simulated, the negative impact on population growth rate per rabbit hunted was clearly higher in autumn than in summer for all scenarios. However, when some degree of sex- and age-selection was considered in the model, the negative impact decreased more quickly during the autumn than during the summer as the degree of selection increased. As expected, under all simulated scenarios compensatory juvenile mortality decreased the negative impact per rabbit hunted on population growth rate. The point where the autumn and summer lines cross in Fig. 2 indicates the degree of sex- and age selection where the negative impact of hunting on growth rate per rabbit hunted was equal for both hunting seasons. Higher degrees of selection than the crossing values imply a lowerimpact on population dynamics per rabbit hunted during the autumn season, and theoretically suggest that a higher number of rabbits could be hunted during this season until the decreasing growth rate reached the same values as those attained during the summer. Location of crossing points in relation to degrees of sexand age-selection was determined in the model by compensatory mechanisms of juvenile mortality and by the turnover level of the population. Crossing points were located at higher degrees of sex-and age selection under conditions of compensatory mortality or when turnover level increased. Under the compensatory scenario, the crossing points of populations with higher turnover were located at higher degrees of sex- and age selection. In this case simulation of a population with $30 \%$ increased mortality had a crossing point near the probability ratio values estimated from logistic regression of the field data (Mean PR in Fig. 2). Under the non-compensatory scenario, however, crossing points for all simulations were located approximately on PR-SE values. That is, at hunting selection probability ratio values estimated in the field, the negative impact on growth rate per rabbit hunted was lower in autumn than in summer for all scenarios simulated.

\section{Discussion}

\subsection{Modelling results}

Several authors have attempted to estimate the optimal control or timing of sustainable hunting of wild rabbit populations by modelling using approximations based on theoretical assumptions (Darwin and Williams, 1964; Smith and Trout, 1994; Smith, 1997; Angulo and Villafuerte, 2003). We have improved on these approximations by constructing a simple theoretical model that includes empirical field estimations of selection of hunting by shotgun.

Smith et al. (1995) suggested that, in general, aboveground methods of capture are biased toward males and within-warren methods toward females, and that some hunting methods, particularly shotgun, result in samples that may not be representative of the age structure of the population. In addition, selectivity of capture methods may vary with the season or even with habitat structure (Daly, 1980). Our field estimations of hunting selection are in accordance with these previous results, and with selective predation carried out by golden eagles (Aquila chrysaetos) and eagle owls (Bubo bubo) on rabbit populations of northern Spain, where young rabbits are more likely to be taken by predators than adults, and males more than females (Donázar and Ceballos, 1989; Fernández and Ceballos, 1990). Behavioural differences regarding sex and age throughout the year seem to be the key determinants in the selection of capture methods and predation, and therefore of hunting by shotgun in both hunting seasons (Mykytowycz, 1960; Arthur, 1980; Soriguer, 1981b; Wheeler et al., 1981; Kolb, 1994).

Model results showed that the tendency to be overharvested was a complex interaction among the timing of hunting, hunting selection, seasonal adult mortality, compensatory juvenile mortality and turnover level of the population. Whereas compensatory juvenile mortality and turnover were factors that affected over-harvesting within hunting seasons, seasonal adult mortality combined with sex- and age-selection were the strongest factors determining the impact of hunting between seasons.

Under the non-compensatory juvenile mortality scenario, the lower natural mortality of the reproductive age class (adults) determined that the tendency to be over-harvested was lower in populations with low turnover levels in summer and for simulations of no hunting selection in the autumn. The higher fecundity of populations with high turnover levels, however, reduced the tendency to be over-harvested when autumn hunting was young- and male-selective. Under the compensatory juvenile mortality scenario, hunting pressure was compensated for more efficiently in summer than in autumn, since compensatory mechanisms influenced population dynamics for a longer period of time before the start of the breeding period. 
The influence of seasonal adult mortality and ageand sex-selection of hunting on the tendency to be over-harvested, can be explained on the basis of the demographic value of an individual, reflecting the expected contribution of the individual to population size over time (Kokko and Lindström, 1998). When non-selective hunting was simulated and mortality rates of adult rabbits varied within the year, the rise in the demographic value of adults was steepest during the time when mortality rates reached their peak (in autumn-winter), and therefore, populations were more prone to over-harvesting in the autumn than the summer hunting season. However, when hunting selection was simulated, the impact of the timing of hunting was mainly determined by the differential reproductive value of individuals harvested during both hunting seasons, since in autumn, the juvenile- and male-biased selection of hunting led to individuals being harvested that did not have reproductive value in the model, i.e., adult and especially juvenile males. Furthermore, age hunting selection during the summer led to the harvesting primarily of male and female juvenile rabbits. During this season a higher proportion of females hunted were subadult individuals, whose reproductive value was lower than that of adult females, but higher than that of young females; i.e., those that are harvested when hunting is simulated during the breeding period (Angulo and Villafuerte, 2003).

Regarding the number of rabbits harvested, hunting selection was the main factor that determined the differences in impact per rabbit hunted on the growth rate of the population between hunting seasons, although their effects were modulated to a great extent by the combination of compensatory juvenile mortality and turnover. For an equivalent impact on growth rate, the summerto-autumn ratio of number of rabbits hunted depended on the seasonal ratio of population density. Higher turnover levels reflected higher rabbit density ratios, and therefore, the summer-to-autumn ratio of number of rabbits hunted increased with turnover level. This effect was enhanced by compensatory juvenile mortality, such that the negative impact on growth rate per rabbit hunted was higher during the autumn than during the summer for low selection probability ratios, but decreased when probability ratios increased.

\subsection{Import on conservation and management policies}

Our model improved previous theoretical approximations to assess the impact of the timing of hunting on wild rabbit populations. However, some assumptions should be taken into account, as the nature of the model was simplistic. This model only assessed the impact of hunting during two defined 2-month periods and generated hunting selection probability ratios for a defined population and habitat. Moreover, this model did not include a stochastic variation of natural populations.
Given the variability of population dynamics of wild rabbit populations in the Iberian Peninsula (Soriguer, 1981a; Villafuerte, 1994; Gonçalves et al., 2002), the exact values of harvesting rates and their impact on population growth rate cannot be taken into account as management rules. Rather, these results should only be used to assess the relative importance of the timing of hunting. In addition, little is known about factors that may determine hunting selection. The influence of population density, habitat structure, hunting pressure, hunting methods and, especially, season of year on hunting selection should be assessed in future intensive surveys and included in new, improved models.

The results obtained here are not in accordance with management policies derived from previous works (Darwin and Williams, 1964; Smith and Trout, 1994; Smith, 1997; Angulo and Villafuerte, 2003), which evaluated the timing of control of hunting in rabbit populations by considering population percentage or number of rabbits hunted as equivalent concepts. We have shown that optimisation of the timing of hunting to avoid the overexploitation of rabbit populations may be dependent on the trade-off between two related but different concepts, the tendency to be over-harvested and the number of rabbits hunted (hunting bags). The simulations here suggest that autumn hunting results in a lower tendency toward over-harvesting populations than summer hunting for a wider range of population dynamic scenarios. In addition, the number of rabbits in hunting bags was not necessarily greater in summer than in autumn, and, in fact, was lower for a wide range of selection probability ratios, including field estimates. For these reasons, we regard altering the main wild rabbit hunting season to summer as inadvisable.

The Spanish and other Governments interested in the conservation of wild rabbits and their consequent effect on high conservation priority of predator species dependent on rabbits should be cautious in considering changes in current hunting policies, as suggested previously (REGHAB, 2002). Rather, we have shown here that the impact of hunting on population dynamics is highly determined by hunting selection, that this can be age- and sex-biased, and that it may vary throughout the year. At the present time, sustainable harvesting schemes for wild rabbit populations cannot be formulated due to a lack of more precise and complete approximations to assess the impact of hunting. Our results are a finest approximation, and they suggest that a maintenance of the current main rabbit hunting season during the autumn-winter period seems to be the most conservative option for the harvesting of wild rabbit populations. Another management option to reduce the hunting impact may be to shorten the hunting season, so that it finishes at the end of autumn, thereby avoiding hunting activity during the winter, when the proportion of pregnant females is highest, they have in- 
creased activity outside the warrens, and this increases their tendency to be hunted. Similarly, hunting during the summer should be only authorised for population control, as it has been carried out in the past, and it should be retrieved as a main hunting season only for populations with high turnover levels.

\section{Acknowledgements}

We thank Emilio Escudero and Angel Ortillés for their help and the "Valdelitera" hunting association for the collaboration of their members during the sampling of hunting bags. The survey was funded by Departamento de Medio Ambiente, Gobierno de Aragón.

\section{References}

Angulo, E., Villafuerte, R., 2003. Modelling hunting strategies for the conservation of wild rabbit populations. Biological Conservation 115, 291-301.

Argüello, J.L., Llanos, A., Perez, L.I., 1988. Enfermedad Hemorrágica del conejo en España. Medicina Veterinaria 5, 645-650.

Arthur, C.P., 1980. Demographie du lapin de garenne Oryctolagus cuniculus (L.) 1758 en région parisienne. Bulletin Mensuel Office National de la Chasse, Decembre 1980, pp. 127-162.

Boyce, M.S., Sinclair, A.R.E., White, G.C., 1999. Seasonal compensation of predation and harvesting. Oikos 87, 419-426.

Boyd, I.L., 1985. Investment in growth by pregnant wild rabbits in relation to litter size and sex of the offspring. Journal of Animal Ecology 54, 137-147.

Calvete, C., Estrada, R., Villafuerte, R., Osácar, J.J., Lucientes, J., 2002. Epidemiology of viral haemorrhagic disease (VHD) and myxomatosis in a free-living populations of wild rabbits. The Veterinary Record 150, 776-782.

Cowan, D.P., 1987. Patterns of mortality in a free-living rabbit (Oryctolagus cuniculus) population. Symposia Zoological Society of London 58, 59-77.

Daly, J.C., 1980. Age, sex and season: factors wich determine the trap response of the European wild rabbit, Oryctolagus cuniculus. Australian Wildlife Research 7, 421-432.

Darwin, J.H., Williams, R.M., 1964. The effect of time of hunting on the size of a rabbit population. New Zealand Journal of Zoology 7, 341-352.

Delibes, M., Hiraldo, F., 1981. The rabbit as prey in the Mediterranean ecosystem. In: Myers, K., MacInnes, C.D. (Eds.), Proceedings of the World Lagomorphs Conference. University of Guelph, Ontario, Canada, pp. 614-622.

Donázar, J.A., Ceballos, O., 1989. Selective predation by eagle owls Bubo bubo on rabbits Oryctolagus cuniculus: age and sex preferences. Ornis Scandinavica 20, 117-122.

Fernández, C., Ceballos, O., 1990. Uneven sex-ratio of wild rabbits taken by golden eagles. Ornis Scandinavica 21, 236-238.

Gibb, J.A., 1993. Sociality, time and space in a sparse population of rabbits (Oryctolagus cuniculus). Journal of Zoology 229, 581-607.

Gonçalves, H., Alves, P.C., Rocha, A., 2002. Seasonal variation in the reproductive activity of the wild rabbit (Oryctolagus cuniculus algirus) in a Mediterranean ecosystem. Wildlife Research 29, 165173.

High-Performance Systems, Inc., 1997. Feature Documentantion, Hanover, NH, USA.
Jensen, A.L., 1996. Density-dependent matriz yield equation for optimal harvest of age-structured wildlife populations. Ecological Modelling 88, 125-132.

Kokko, H., Lindström, J., 1998. Seasonal density dependence, timing of mortality, and sustainable harvesting. Ecological Modelling 110, 293-304.

Kolb, H.H., 1994. The use of cover and burrows by a population of rabbits (Mammalia: Oryctolagus cuniculus) in eastern Scotland. Journal of Zoology 233, 9-17.

Ministry of Agriculture, Fisheries and Food, 1996. Agricultural Statistics Yearbook, Spain.

Muñoz, G., 1960. Anverso y reverso de la mixomatosis, first ed. Dirección General de Montes, Caza y Pesca Fluvial, Madrid.

Myers, K., Poole, W.E., 1962. A study of the biology of the wild rabbit, Oryctolagus cuniculus (L.) in confined populaitons. III. Reproduction. Australian Journal of Zoology 10, 225-267.

Mykytowycz, R., 1960. Social behaviour of an experimental colony of wild rabbits, Oryctolagus cuniculus (L.). III. Second breeding season. CSIRO Wildlife Research 5, 1-20.

Palma, L., Beja, P., Rodríguez, M., 1999. The use of sighting data to analyse Iberian lynx habitat and distribution. Journal of Applied Ecology 36, 812-824.

Palomares, F., 2001. Vegetation structure and prey abundance requirements of the Iberian lynx: implications for the design of reserves and corridors. Journal of Applied Ecology 38, 9-18.

REGHAB, 2002. Reconciling gamebird hunting and biodiversity. V Forework Program of the European Union. Proposal No.: EKV2000-00637, Geneva, Switzerland.

Rodríguez, A., Delibes, M., 2003. Population fragmentation and extinction in the Iberian lynx. Biological Conservation 109, 321331.

Selvin, S., 1996. Statistical Analysis of Epidemiologic Data. Oxford University Press, Oxford.

Shepherd, R.C.H., Edmonds, J.W., Nolan, I.F., 1981. Observations on variations in the sex ratios of wild rabbits, Oryctolagus cuniculus (L.), in Victoria. Australian Wildlife Research 8, 361-367.

Smith, G.C., 1997. An analysis of the form of density dependence in a simulation model of a seasonal breeder undergoing control. Ecological Modelling 95, 181-189.

Smith, G.C., Pugh, B., Trout, R.C., 1995. Age and sex bias in samples of wild rabbits, Oryctolagus cuniculus, from wild populations in southern England. New Zealand Journal of Zoology 22, 115-121.

Smith, G.C., Trout, R.C., 1994. Using Leslie matrices to determine wild rabbit population growth and the potential for control. Journal of Applied Ecology 31, 223-230.

Soriguer, R.C., 1981a. Biología y dinámica de una población de conejos (Oryctolagus cuniculus, L.) e Andalucía Occidental. Doñana. Acta Vertebrata 8, 1-378.

Soriguer, R.C., 1981b. Estructura de edades y sexos en una población de conejos (Oryctolagus cuniculus L.) de Andalucía occidental. Doñana. Acta Vertebrata 8, 225-236.

Trout, R.C., Smith, G.C., 1998. Long- term study of litter size in relation to population density in rabbits (Oryctolagus cuniculus) in Lincolnshire, England. Journal of Zoology 246, 347-350.

Trout, R.C., Tittensor, A.M., 1989. Can predators regulate wild rabbit Oryctolagus cuniculus population density in England and Wales? Mammal Review 19, 153-173.

Tyndale-Biscoe, C.H., Williams, R.M., 1955. A study of natural mortality in a wild population of the rabbit, Oryctolagus cuniculus. New Zealand Journal of Science and Technology B 36, 561-580.

Twigg, L.E., Williams, C.K., 1999. Fertility control of overabundant species: can it work for feral rabbits?. Ecology Letters 2, 281285.

Villafuerte, R., 1994. Riesgo de predación y estrategias defensivas del conejo, Oryctolagus cuniculus, en el Parque Nacional de Doñana. Ph.D. Thesis, Universidad de Córdoba, Córdoba, Spain. 
Villafuerte, R., Calvete, C., Blanco, J.C., Lucientes, J., 1995. Incidence of viral hemorrhagic disease in wild rabbit populations in Spain. Mammalia 59, 651-659.

Watson, J.S., Tyndale-Biscoe, C.H., 1953. The apophyseal line as an indicator of age for the wild rabbit (Oryctolagus cuniculus L.). New Zealand Journal of Science and Technology 34, 427-435.
Wheeler, S.H., King, D.R., 1985. The European rabbit in Southwestern Australia. III. Survival. Australian Wildlife Research 12, 213-225.

Wheeler, S.H., King, D.R., Robinson, M.H., 1981. Habitat and warren utilization by the European rabbit, Oryctolagus cuniculus (L.), as determined by Radio-Tracking. Australian Wildlife Research $8,581-588$. 